\title{
Attenuating immune pathology using a microbial-based intervention in a mouse model of cigarette smoke-induced lung inflammation
}

Mark Bazett ${ }^{1}$, Agnieszka Biala², Ryan D. Huff', Matthew R. Zeglinksi ${ }^{3}$, Philip M. Hansbro ${ }^{4}$, Momir Bosiljcic $^{1}$, Hal Gunn ${ }^{1}$, Shirin Kalyan ${ }^{1,5}$ and Jeremy A. Hirota ${ }^{2,6^{*}}$

\begin{abstract}
Background: Cigarette smoke exposure is the major risk factor for developing COPD. Presently, available COPD treatments focus on suppressing inflammation and providing bronchodilation. However, these options have varying efficacy in controlling symptoms and do not reverse or limit the progression of COPD. Treatments strategies using bacterial-derived products have shown promise in diseases characterized by inflammation and immune dysfunction. This study investigated for the first time whether a novel immunotherapy produced from inactivated Klebsiella (hereafter referred to as KB) containing all the major Klebsiella macromolecules, could attenuate cigarette smoke exposure-induced immune responses. We hypothesized that KB, by re-directing damaging immune responses, would attenuate cigarette smoke-induced lung inflammation and bronchoalveolar (BAL) cytokine and chemokine production.

Methods: KB was administered via a subcutaneous injection prophylactically before initiating a 3-week acute nose-only cigarette smoke exposure protocol. Control mice received placebo injection and room air. Total BAL and differential cell numbers were enumerated. BAL and serum were analysed for 31 cytokines, chemokines, and growth factors. Lung tissue and blood were analysed for $\mathrm{Ly}_{6} \mathrm{C}^{\mathrm{HI}}$ monocytes/macrophages and neutrophils. Body weight and clinical scores were recorded throughout the experiment.

Results: We demonstrate that $\mathrm{KB}$ treatment attenuated cigarette smoke-induced lung inflammation as shown by reductions in levels of BAL IFNY, CXCL9, CXCL10, CCL5, IL-6, G-CSF, and IL-17. KB additionally attenuated the quantity of BAL lymphocytes and macrophages. In parallel to the attenuation of lung inflammation, KB induced a systemic immune activation with increases in Ly6 $\mathrm{C}^{\mathrm{HI}}$ monocytes/macrophages and neutrophils.

Conclusions: This is the first demonstration that subcutaneous administration of a microbial-based immunotherapy can attenuate cigarette smoke-induced lung inflammation, and modulate BAL lymphocyte and macrophage levels, while inducing a systemic immune activation and mobilization. These data provide a foundation for future studies exploring how KB may be used to either reverse or prevent progression of established emphysema and small airways disease associated with chronic cigarette smoke exposure. The data suggest the intriguing possibility that KB, which stimulates rather than suppresses systemic immune responses, might be a novel means by which the course of COPD pathogenesis may be altered.
\end{abstract}

Keywords: COPD, Immunomodulators, Klebsiella, mucosal immunology

\footnotetext{
* Correspondence: hirotaja@mcmaster.ca

${ }^{2}$ Department of Medicine, Division of Respiratory Medicine, University of

British Columbia, Vancouver, BC, CanadaV6H $3 Z 6$

${ }^{6}$ Firestone Institute for Respiratory Health, Division of Respirology,

Department of Medicine, McMaster University, Hamilton, ON, CanadaL8N

$4 \mathrm{~A} 6$

Full list of author information is available at the end of the article
} 


\section{Background}

Chronic obstructive pulmonary disease (COPD) is an inflammatory airway disease that results in progressive irreversible airflow limitation. The global prevalence of COPD, as determined by the World Health Organization, is $11.7 \%$ [1], and it is predicted that by 2030 it will be the fourth leading cause of death worldwide [2]. Mainstream or second-hand cigarette smoke exposure is a risk factor for developing COPD [3], which can be exacerbated by genetic factors $[4,5]$ and environmental exposures $[6,7]$. Chronic cigarette smokers that develop COPD may present with varying degrees of cough, sputum production, dyspnea, wheezing, and chest tightness [8, 9]. Presently, available treatments primarily focus on suppressing inflammation and providing bronchodilation. However, these options have varying efficacy in controlling symptoms and do not reverse or limit, completely, the progression of COPD [10, 11].

The pathology of COPD includes emphysema and obstruction of the small airways as a result of chronic bronchitis, which is associated with inflammation and immune dysfunction [12, 13]. In COPD patients, the inflammatory immune response is altered, and often involves increased cytokines, including IFN- $\gamma$, CXCL9 (MIG), CXCL10 (IP-10), and CCL5 (RANTES) [14-16]. This lung cytokine and chemokine milieu recruits and activates inflammatory cells including neutrophils, macrophages, $\mathrm{B}$ cells, CD4+ T cells, and CD8+ T cells $[17,18]$. In addition to inflammation, abnormal immune function has also been described in COPD patients, including altered macrophage function [19]. Treatment options that can target the immune skewing and dysfunction, rather than broad immune repression, may present a more attractive approach to manage cigarette smoke-induced COPD.

Treatments strategies using bacterial-derived products have shown promise in diseases characterized by inflammation and immune dysfunction [20-23]. This has primarily been demonstrated in animal models of allergic airway disease where different treatment strategies using bacteria or bacterial derived products have been used to modulate immune responses [20-22, 24]. Towards that end, intervention strategies encompassing everything from live bacteria to specific pattern recognition receptor agonists have been used in models of allergic airway disease [21, 22, 25-27]. The apparent mechanism of action works through a reduction in inflammation and an altering of the immune response. In studies of smoking-induced lung disease, Lactobacillus rahmnosus and Bifidobacterium breve have been shown to attenuate pro-inflammatory cytokine production in a macrophage cell line treated with cigarette smoke extract [28].

The current study investigated for the first time whether a novel immunotherapy produced from inactivated Klebsiella (hereafter referred to as $\mathrm{KB}$ ) containing all the major Klebsiella macromolecules, would attenuate maladaptive cigarette smoke exposure-induced immune responses. We hypothesized that KB would re-direct damaging immune responses and attenuate cigarette smoke-induced lung cellular inflammation and bronchoalveolar lavage (BAL) cytokine and chemokine production. We demonstrate that subcutaneous administration of $\mathrm{KB}$ attenuated cigarette smoke-induced lung inflammation and the quantity of airway BAL lymphocytes and macrophages while inducing systemic immune activation mimicking the response to acute infection.

\section{Methods}

\section{Animals}

Female mice C57BL/ 6 age 8-10 weeks old were purchased (Jackson Labs, Farmington, Connecticut, USA), acclimatized, and housed for one additional week prior to the commencement of experiments. Female mice were used as recent studies suggest that they are more susceptible to cigarette smoke induced lung pathology, as are women compared to men [29]. The experiments included ten mice per group, which were housed as five mice per cage in environmentally-controlled specific pathogen free conditions with a 12:12 h light/dark cycle for the duration of the study. All protocols were reviewed and approved by the Animal Care Committee of the University of British Columbia (Vancouver, BC, Canada).

\section{Cigarette/air smoking protocol}

Air or cigarette smoke exposure was done for five consecutive days for the first 2 weeks and for four consecutive days in the third week (experimental days: $1-5 ; 8-12$, 15-18, Fig. 1). Mice were euthanized $24 \mathrm{~h}$ after the last exposure (experimental day 19). Briefly, cigarette smoke exposure (University of Kentucky Research Grade Cigarettes) was performed by placing mice into plexiglass "nose only" exposure chambers as previously described $[29,30]$. Each mouse smoked three cigarettes per day for a total of $45 \mathrm{~min}$ of exposure. Control room air-exposed mice were restrained for a similar duration without exposure to smoke. Animals were monitored throughout the smoke exposure procedure and for an additional $30 \mathrm{~min}$ post-smoke exposure.

\section{Microbe-based intervention strategy}

The microbe-based intervention, $\mathrm{KB}$, is a proprietary immunomodulator consisting of all major macromolecules of an inactivated pathogenic Klebsiella strain was originally isolated from a patient with acute pneumonia. KB was supplied by $\mathrm{Qu}$ Biologics (Vancouver, BC). For the treatment intervention, $\mathrm{KB}$ or a placebo vehicle control (physiological saline containing $0.4 \%$ phenol) was prophylactically administered on the experimental day $-7,-5,-3$, and the regimen continued throughout the 


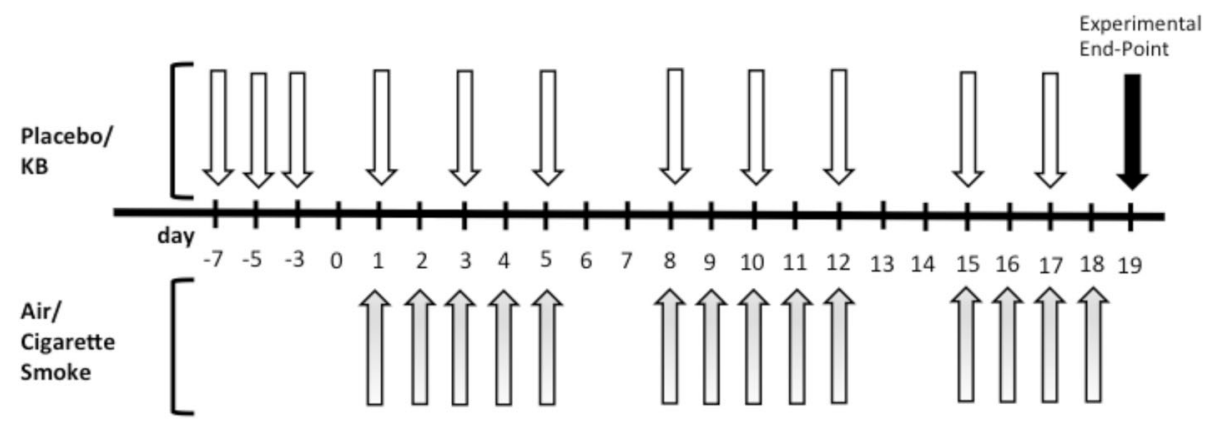

Fig. 1 Cigarette smoke exposure protocol with Klebsiella (KB) intervention. Four groups of mice were exposed to either placebo + room air, KB + room air, placebo + cigarette smoke, or KB + cigarette smoke. Grey arrows, room air or cigarette smoke; white arrows, subcutaneous injection of placebo or KB. See methods for details

experiment on days 1, 3, 5, 8, 10, 12, 15, 17 (Fig. 1). Each administration involved a subcutaneous injection of $30 \mu \mathrm{L}$ of placebo or $\mathrm{KB}$, which was alternatively delivered into the lower right abdomen, the lower left abdomen, the upper right chest, and the upper left chest, rotating clockwise for each injection day.

\section{Blood collection, BAL, and cytospin analysis of BAL cell differentials}

Processing and analysis of collected terminal blood and BAL samples was done as described previously [22]. Cytospins were performed and cells in BAL evaluated based on morphology and Wright-Giemsa staining. BAL cell differentials were then counted using the prepared cytospin slide with 100 cells per mouse counted in a blinded fashion.

\section{Immune mediator profiling of BAL and serum samples}

Soluble mediator analysis in BAL and serum was performed using a 31 cytokine, chemokine, growth factor multiplex kit according to the manufacturer's protocol (Millipore, St. Charles, MO, USA) using the Bio-Plex ${ }^{\mathrm{TM}} 200$ system (Bio-Rad Laboratories, Inc., Hercules, CA, USA). The multiplex was performed by Eve Technologies (Eve Technologies Corp, Calgary, AB, Canada). The 31-plex assay included the following mediators: Eotaxin, G-CSF, GM-CSF, IFN $\gamma$, IL-1 $\alpha$, IL-1 $\beta$, IL-2, IL-3, IL-4, IL-5, IL-6, IL-7, IL-9, IL-10, IL-12 (p40), IL-12 (p70), IL-13, IL-15, IL-17, IP-10 (CXCL10), KC (CXCL1), LIF, MCP-1 (CCL2), M-CSF, MIG (CXCL9), MIP-1 $\alpha$ (CCL3), MIP-1 $\beta$ (CCL4), MIP-2 (CXCL2), RANTES (CCL5), TNF $\alpha$, and VEGF. The assay sensitivities of these markers range from 0.1 $33.3 \mathrm{pg} / \mathrm{mL}$.

\section{Flow cytometric analysis of $\mathrm{Ly}_{6 \mathrm{C}} \mathrm{HI}$ monocytes/ macrophages and neutrophils}

Blood was collected in EDTA coated tubes (BD Microtainer) to prevent clotting and stored on ice prior to staining. Anti-coagulant-treated whole blood was stained with antibodies (CD11b-FITC, Ly6G-PE, CD11cPerCPCy5.5 and Ly6C-APC) before red blood cell lysis (BD lysis buffer). Flow cytometry was run on a FACSCalibur (BD Bioscience). Analysis was completed using the FlowJo V10.1 program. Neutrophils were defined as Ly $6 \mathrm{G}^{+} \mathrm{CD} 11 \mathrm{~b}^{+}$cells. Ly6C ${ }^{\mathrm{HI}}$ monocytes/macrophage were defined as $\mathrm{Ly}_{6 \mathrm{C}} \mathrm{HI}^{\mathrm{HI}} 6 \mathrm{G}^{-} \mathrm{CD} 11 b^{+}$cells. Lymphocyte populations were gated on by forward scatter and side scatter and then defined as $\mathrm{B} 220^{+}, \mathrm{CD}^{+} \mathrm{CD}^{+}$, or $\mathrm{CD} 3$ ${ }^{+} \mathrm{CD}^{+}$.

\section{Data analysis}

GraphPad Prism 6 Software (GraphPad Software, San Diego, CA) was used to perform statistical analysis of the results. Data are expressed as mean $\pm \mathrm{SD}$. One-way ANOVA analysis followed by multiple comparisons using a Sidak post-hoc test was performed for group comparisons. Four experimental group combinations were compared; room air-placebo vs. room air-KB, room air-placebo vs. cigarette smoke-placebo, room air-KB vs. cigarette smoke-KB, cigarette smoke-placebo vs. cigarette smoke-KB. Differences were reported as statistically significant when $p<0.05$.

\section{Results}

KB attenuated cigarette smoke exposure-induced influx of lymphocytes and macrophages, but not neutrophils into the airways

A three-week acute model of cigarette smoke exposure in mice (Fig. 1) was used to investigate how KB exposure can modulate lung inflammation. The total BAL cell counts and cellular differentials for each experimental group were assessed (Fig. 2). In placebo treated animals, cigarette smoke exposure increased the total number of BAL cells (Fig. 2a, $p<0.0001$ ). The observed increase in cellularity resulted from increases in the numbers of lymphocytes, macrophages, and neutrophils (Fig. 2b, d, $p<0.0001)$, but not eosinophils $(p=0.35$, data not shown). KB intervention did not significantly decrease 

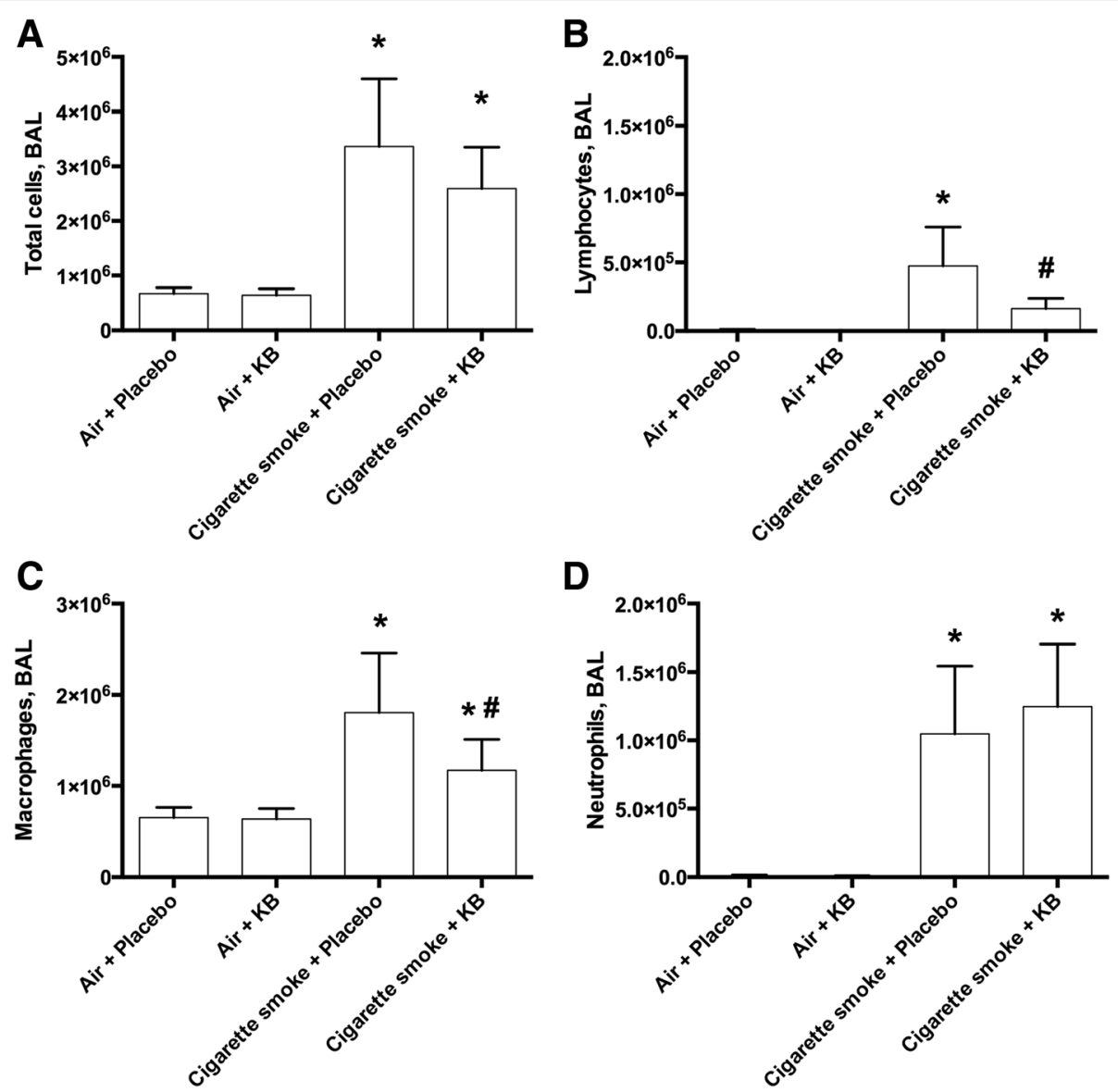

Fig. 2 KB treatment attenuated cigarette smoke exposure induced increases in airway macrophages and lymphocytes but not total cells or neutrophils. BAL cell counts and differentials following placebo and KB treatment in room air or cigarette smoke-exposed groups. a BAL total cells, $\mathbf{b}$ lymphocytes, $\mathbf{c}$, macrophages $\mathbf{d}$, and neutrophils. ${ }^{*} p<0.05$ comparing to the groups relative control; $\# p<0.05$ comparing KB group to relative placebo control. Data are means \pm SD of $9-10$ mice per group

the total number of BAL cells, however it did attenuate the increase in lymphocytes and macrophages in the cigarette smoke-exposed group $(p<0.005$, Fig. 2b-c) while having no detectable impact on neutrophils (Fig. 2d, $p=0.59$ ).

\section{KB intervention attenuated cigarette smoke exposure- induced lung inflammatory responses}

Previous reports have demonstrated that cigarette smoke exposure models are characterized by a cytokine profile that includes IFN- $\gamma$, CXCL9 (MIG), CXCL10 (IP-10), and CCL5 (RANTES) [14, 15]. A multiplex analysis of 31 cytokines, chemokines, and growth factors (Additional file 1: Table S1) was used to investigate cytokine and chemokine production induced by cigarette smoke exposure in this experimental system. KB intervention had no impact on air-exposed animals for any mediator measured in the BAL fluid. Cigarette smoke exposure induced 15 of the 31 measured mediators in the BAL fluid, which were IFN $\gamma$, CXCL9, CXCL10, CCL5, IL-6, IL-17, G-CSF, CXCL1, LIF,
CCL2, CCL3, CCL4, TNF $\alpha$, eotaxin, and VEGF $(p<0.05)$. Although IL-17 was elevated with cigarette smoke exposure, this was only observed in 4 of 10 samples and the values were close to the level of detection for this cytokine $(0.64 \mathrm{pg} / \mathrm{ml})$. KB intervention attenuated cigarette smoke-induced increases in IFN $\gamma$, CXCL9, CXCL10, CCL5, IL-6, G-CSF, and IL-17 (Fig. 3, $p<0.05$ ) in the BAL fluid. KB also decreased TNF $\alpha$ levels (cigarette smoke + placebo $7.50 \pm 5.98 \mathrm{pg} / \mathrm{ml}$ vs cigarette smoke + $\mathrm{KB} 3.52 \pm 3.34 \mathrm{pg} / \mathrm{ml}$ ), but this was not statistically significant $(P=0.057$, Additional file 1: Table S1).

Systemic immune cytokine, chemokine and growth factor profile were not significantly altered with 3-week cigarette smoke exposure, but were augmented by KB exposure

When assessing changes in the serum levels of cytokine, chemokines and growth factors in the experimental treatment groups, it was found that cigarette smoke exposure induced an increase in only VEGF, and this was not 


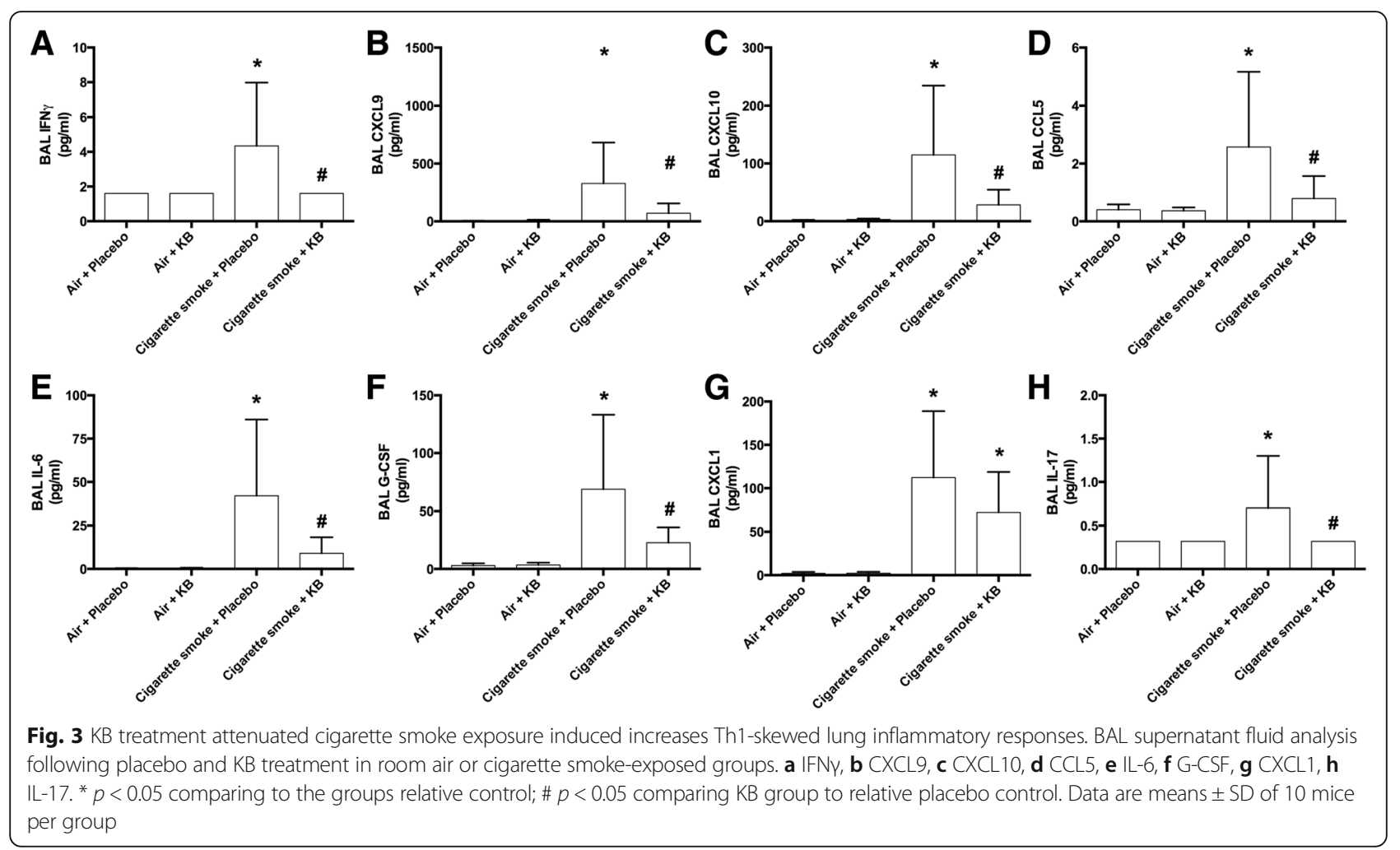

changed with the KB intervention (Fig. 4a, $p<0.05$; Additional file 2: Table S2). KB treatment in air-exposed animals decreased only one mediator, IL12p40, while increasing serum levels of IL-1 $\beta$, CCL2, CXCL9, and CXCL10 (Fig. 4b-d, $p<0.05$ ). In the cigarette smokeexposed mice, treatment increased the levels of CXCL9, CXCL10, and CCL5 relative to cigarette smoke + placebo treated groups $(p<0.05)$. Collectively these data suggest that $\mathrm{KB}$ intervention induced systemic immune responses that are independent of cigarette smoke exposure, which may play a role in the observed local down-regulation of cigarette smoke exposure-induced lung inflammation.

KB induced both a systemic and local lung tissue increase in the proportion of $\mathrm{Ly}_{6} \mathrm{C}^{\mathrm{HI}}$ monocytes/macrophages and neutrophils, with no change in lymphocyte populations

To investigate if the $\mathrm{KB}$ intervention altered systemic or local cellular immune profiles, blood and lung cells were assessed by flow cytometry, with particular focus on the levels of Ly6C $\mathrm{CH}^{\mathrm{HI}}$ monocytes (an inflammatory subgroup of monocytes, characterized as $\mathrm{Ly}_{6 \mathrm{G}}{ }^{-} \mathrm{CD} 11 \mathrm{~b}^{+}$cells) and neutrophils (characterized as $\mathrm{Ly}_{6} \mathrm{G}^{+} \mathrm{CD} 11 \mathrm{~b}^{+}$cells). Cigarette smoke exposure had no effects on the numbers of blood Ly6C $\mathrm{HI}^{\mathrm{HI}}$ monocytes or neutrophils (Fig. 5a-b, $p>0.6)$. $\mathrm{KB}$ intervention increased the blood $\mathrm{Ly}_{6 \mathrm{C}} \mathrm{HI}$ monocytes and neutrophils in the cigarette smoke exposure groups $(p<0.005)$, and the neutrophils in the air-exposed animals $(p=0.05)$. The increases in systemic
Ly6 $\mathrm{C}^{\mathrm{HI}}$ monocytes and neutrophils were associated with local increases in the lung tissue (Fig. 5c-d), where KB induced increases in these cell types, which was further enhanced by cigarette smoke exposure $(p<0.05)$.

The levels of $\mathrm{B}$ and $\mathrm{T}$ lymphocytes were also assessed in the lungs. The percentage of B cells in the lungs after smoke exposure was elevated (Fig. 6a, $p<0.05$ ), which was not attenuated by KB administration. No statistically significant change in the percentage of $\mathrm{CD}^{+} \mathrm{CD} 4^{+}$or $\mathrm{CD}^{+} \mathrm{CD}^{+}$cells was observed following cigarette smoke exposure or $\mathrm{KB}$ administration (Fig. 6b-c).

Intervention with KB had no impact on clinical score and body weight following cigarette smoke exposure

Body weight and clinical score was used to monitor the overall health of mice exposed to cigarette smoke in the presence or absence of $\mathrm{KB}$. Body weight was normalized to the starting weight of each animal and all animals were observed throughout the experiment and their health assessed based on a clinical score (e.g. hunched posture, interaction with other animals, activity levels). KB administration in the air-exposed group did not significantly alter the body weight (Fig. 7) nor impact the clinical score (data not shown). No adverse effects of repeated KB administration were observed. Cigarette smoke-exposed mice had a prominent loss in body weight $(p<0.05)$, which KB intervention did not attenuate $(p>0.05)$. 


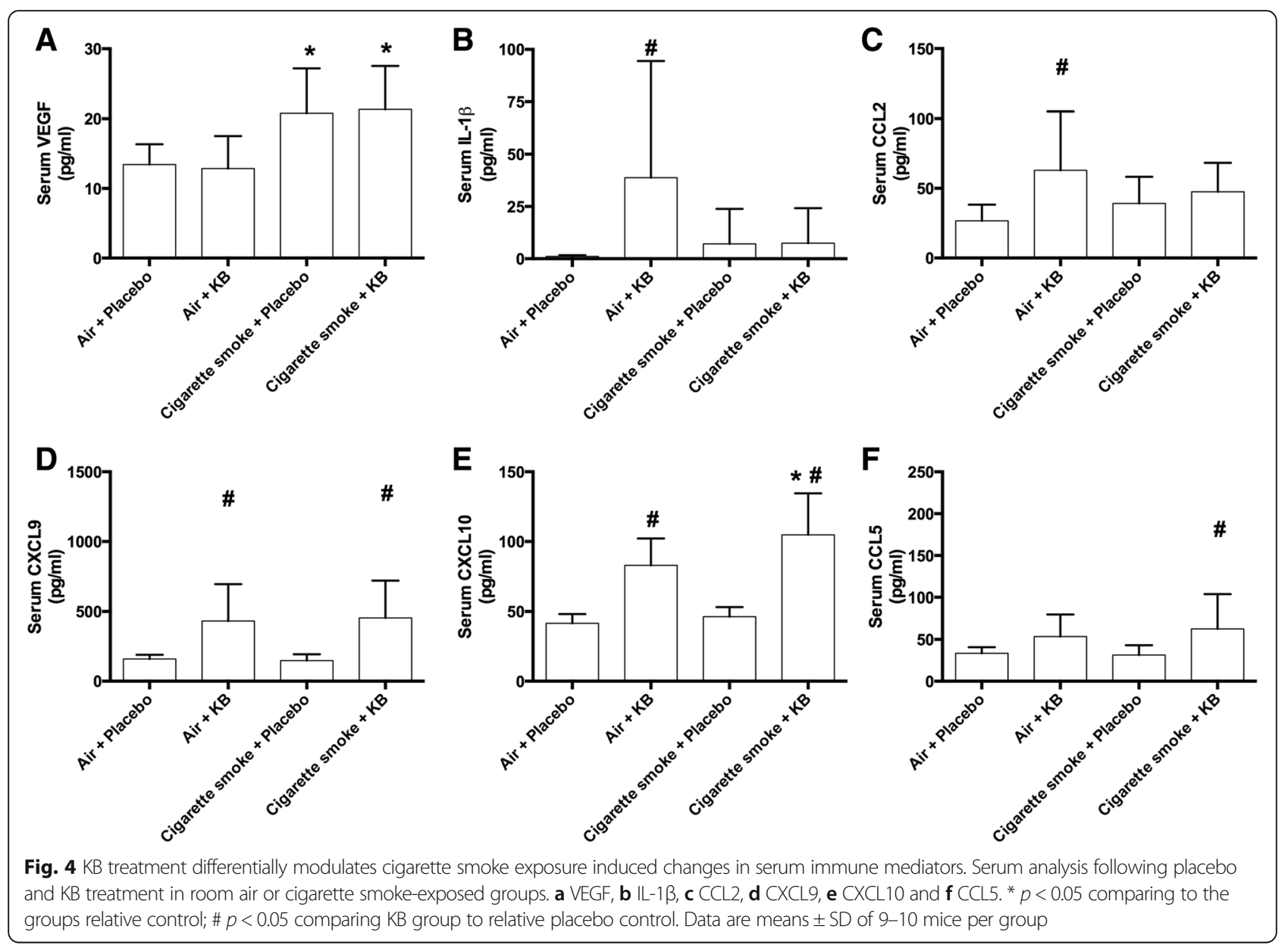

Cigarette smoke exposure did not significantly changed the clinical score for either placebo or KB-treated mice.

\section{Discussion}

There is growing awareness that exposure to microbial products can alter the course of inflammatory diseases. In asthma, several studies have demonstrated promising results for resolution of symptoms with microbial products in both animal models and clinical studies [21, 22, 24-27]; however, there is a paucity of data looking into the use of these approaches aimed at modulating the course of the immune dysfunction in COPD [31]. In this study, we tested the hypothesis that $\mathrm{KB}$, which was produced from a clinical Klebsiella isolate containing all the major Klebsiella macromolecules, could modulate airway inflammation and immune responses in a mouse model of acute cigarette smoke exposure. These results demonstrate that prophylactic KB treatment attenuated both cigarette smoke-induced lung inflammation and BAL macrophage and lymphocyte cellularity. In control room air-exposed and experimental cigarette smoke-exposed animals, KB induced systemic immune responses, resulting in mobilization of monocytes and neutrophils. This systemic immune modulation was mirrored locally in lung tissue, reflected by an increase in $\mathrm{Ly} 6 \mathrm{C}^{\mathrm{HI}}$ monocytes/macrophages and neutrophils. These data therefore suggest that interventions with microbial components that enhance rather than suppress immune responses may provide a novel strategy to alter the course of cigarette smoke exposure related COPD pathogenesis. Future therapeutic intervention-dosing strategies will be aimed at determining how late in the course of smoke-induced lung damage such a microbe-based intervention strategy can be administered to reverse pathology.

Chronic cigarette smoke exposure in humans is associated with emphysema and chronic bronchitis in COPD patients. Acute cigarette smoke exposure can lead to inflammatory responses that may be important preceding events in the chronic changes to lung physiology [32]. The mouse model of acute cigarette smoke exposure used in this study was designed to determine the impact of $\mathrm{KB}$ on modulating these earlier alterations in the inflammatory response and not the chronic bronchitic or emphysematous phenotype observed in chronic mouse cigarette smoke exposure models [29, 33-38]. This study therefore focused on outcome measurements that are impacted by 

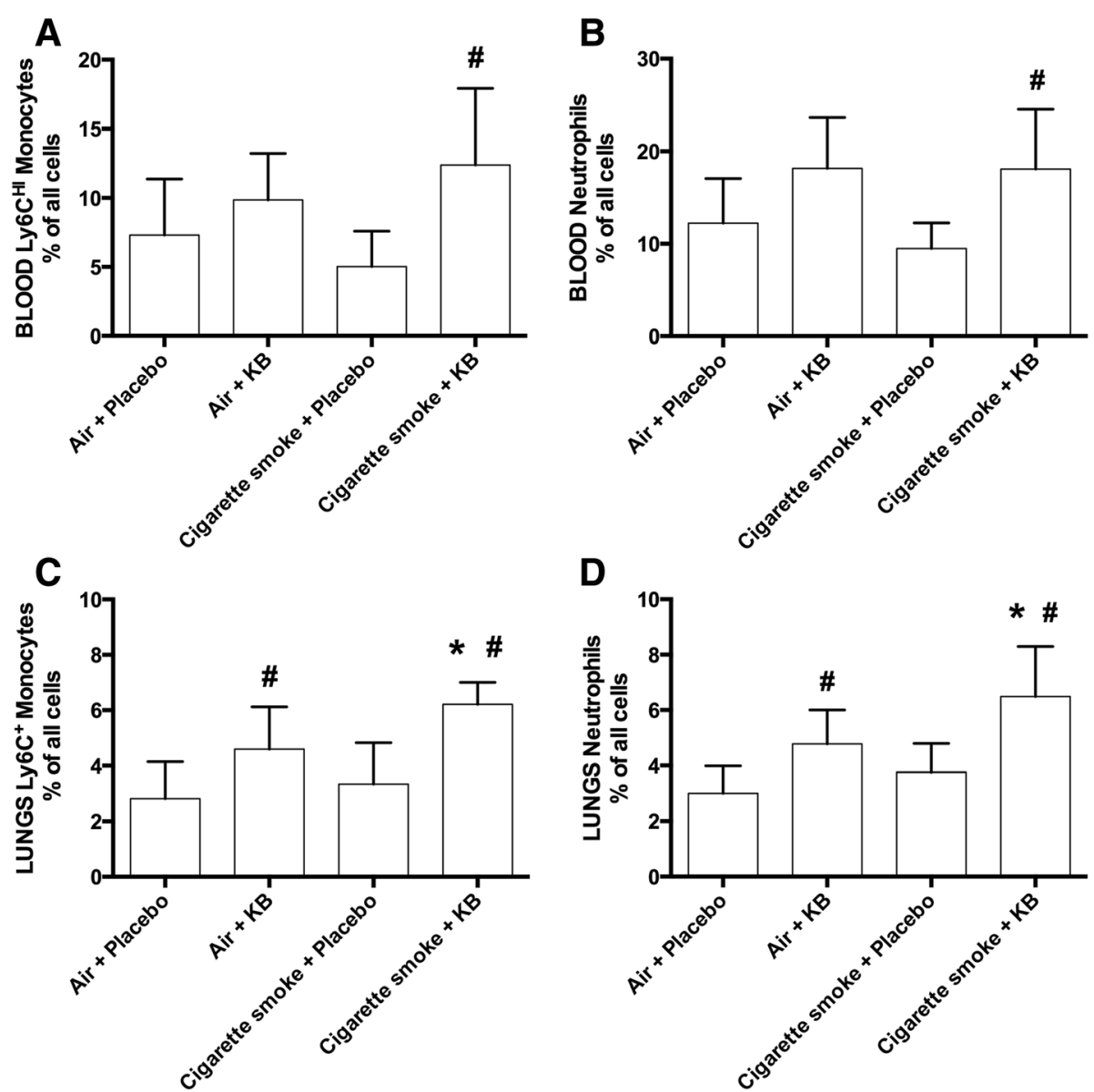

Fig. 5 KB treatment increased blood and lung Ly6 $\mathrm{C}^{\mathrm{HI}}$ monocytes and neutrophils. Flow cytometric analysis of blood $\mathbf{a}-\mathbf{b}$ and lung $\mathbf{c}-\mathbf{d} \mathrm{Ly} 6 \mathrm{C}^{\mathrm{HI}}$ monocytes and neutrophils following placebo and KB treatment in room air or cigarette smoke-exposed groups. ${ }^{*} p<0.05$ comparing to the groups relative control. \# $p<0.05$ comparing KB group to relative placebo control. Data are means \pm SD of 10 mice per group
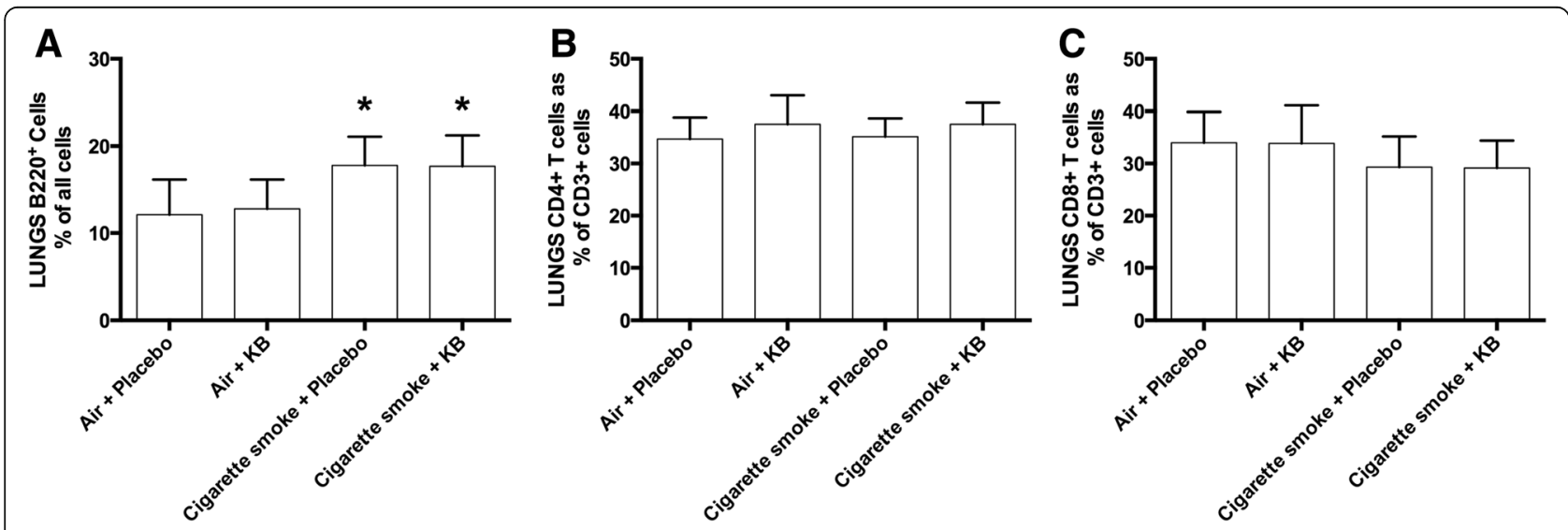

Fig. $6 \mathrm{~KB}$ treatment has no impact on lung B220+ cells, CD3 + CD4+, or CD3 + CD8+ T cells. Flow cytometric analysis of lung a B220+ B cells, b CD3 $+\mathrm{CD} 4+\mathrm{T}$ cells, or $\mathbf{c} \mathrm{CD} 3+\mathrm{CD} 8+\mathrm{T}$ cells following placebo and KB treatment in room air or cigarette smoke-exposed groups. ${ }^{*} p<0.05$ comparing to the groups relative control. Data are means \pm SD of 10 mice per group 


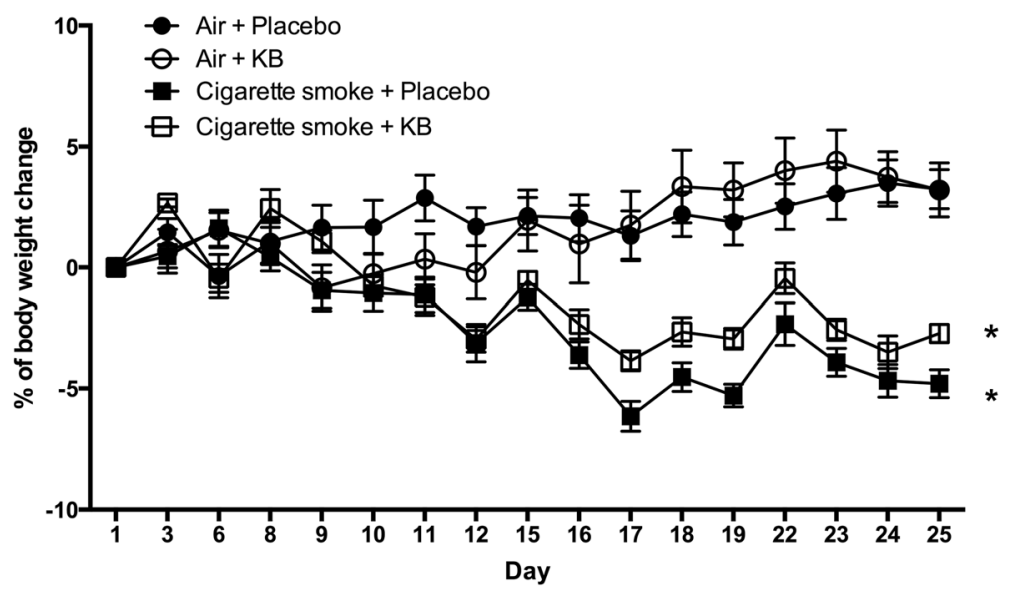

Fig. 7 Cigarette smoke exposure impaired body weight gain independent of KB treatment. Daily measurements of mice were normalized to starting weight for each of the four groups. ${ }^{*} p<0.05$ comparing to the group's relative control. Data are means \pm SD of 10 mice per group

acute cigarette smoke exposure, including lung inflammation resulting from smoke-induced tissue damage, systemic inflammation, immune cell activation, and body weight.

Cigarette smoke exposure-induced inflammation has been described as $\mathrm{T}_{\mathrm{H}} 1$ skewed, although this may be an over simplification [14, 15]. Changes in inflammatory mediators are accompanied by elevations in macrophages, lymphocytes, and neutrophil populations [17, 18, 32]. IFN- $\gamma$ has been implicated as an important participant in the development of emphysematous lesions following cigarette smoke exposure in mice [16] and has been associated with COPD in humans $[14,15]$. IFN- $\gamma$ induces the CXCR3 ligands, CXCL9 (MIG) and CXCL10 (IP-10) [39] and the CCR5 ligand, CCL-5 (RANTES) [16] which recruit lymphocytes and macrophages to sites of inflammation. Importantly, blocking this response protects mice from the pathological impacts of cigarette smoke exposure $[16,40]$. KB intervention was found to specifically attenuate cigarette smoke-induced elevations in IFN- $\gamma$, CXCL9, CXCL10, CCL-5, and IL-6 in the BAL, which was uncoupled from systemic immune activation. This reduction in BAL inflammatory mediators was associated with a concomitant reduction in macrophage and lymphocyte recruitment to the airways. Future mechanistic studies are required to determine how modulation of systemic immune function alters the progression of lung immunity important in chronic models of cigarette smoke exposure.

COPD pathology has many pathologic pathways in common with other inflammatory diseases, including asthma and inflammatory bowel disease (IBD). In these indications, microbial products are actively under investigation as treatment options [23, 24, 31, 41]. IBD and COPD share common pathology relating to mucosal barrier disruption including an altered microbiome, immune dysfunction, altered epithelial cell function, and chronic inflammation [31, 41, 42]. Live microbial products are currently being tested for efficacy in IBD [43, 44]. Furthermore, a product that is prepared in a similar manner to $\mathrm{KB}$, but produced from Escherichia coli, has shown evidence of efficacy in IBD patients [45] and is currently being investigated in clinical trials as a treatment for IBD. There is also significant overlap between asthma and COPD including altered respiratory microbiome and immune dysfunction [31, 42, 46, 47]. In animal models of allergic asthma, live bacteria and their components [24, 27, 48, 49], Toll-like receptor (TLR) agonists [50], and the $\mathrm{KB}$ product [22], have all reduced lung inflammation. Collectively, the primary research presented in this report and the studies outlined above demonstrate some of the similarities between COPD and other inflammatory diseases that benefit from microbial intervention strategies. Taken together, these findings suggest that enhancing or resetting the immune response with bacterial products could be a novel therapeutic approach to managing COPD.

Systemically, these data showed that KB administration, which contains all the major macromodules from the Klebsiella, increased certain cytokines conventionally considered as being pro-inflammatory cytokines, such as $\mathrm{IL}-1 \beta$, as well as the proportion of blood $\mathrm{Ly} 6 \mathrm{C}^{\mathrm{HI}}$ monocytes and neutrophils, similar to the response seen with an acute infection [51-54]. This immune activation and mobilization was also detected in the lung tissue by flow cytometry where an increase in the proportion of monocytes and neutrophils was observed. Conversely, the airways of $K B$ treated animals showed a reduction in the macrophage and lymphocyte levels. This duality of the increased inflammation in the lung tissue and decreased inflammation in the airways highlights the importance of where the immune response occurs for resolution of 
symptoms. Although the precise mechanism(s) of this phenomenon are not yet clear, the prevailing evidence suggests that inflammatory monocytes can differentiate into multiple different cells types in inflamed/damaged tissue $[19,55,56]$ and that enhancement of immune function in the correct tissue-microenvironment may paradoxically contribute to an attenuation in overall inflammation, potentially by clearing necrotic/damaged tissue and rebuilding the loss of barrier function. Indeed, the observed increase in the number of lung $\mathrm{Ly} 6 \mathrm{C}^{\mathrm{HI}} / \mathrm{CD} 11 \mathrm{~b}^{+}$ inflammatory monocytes may have the ability to suppress inflammation [56-58].

\section{Conclusions}

Our study shows that $\mathrm{KB}$, produced from a clinical Klebsiella isolate, can suppress the progression of local airway immune responses and lymphocyte and macrophage influx, while inducing a systemic inflammatory response, in a mouse model of acute cigarette smokeinduced lung inflammation. This is the first demonstration that subcutaneous administration of a microbial derived intervention, $\mathrm{KB}$, can attenuate cigarette smokeinduced inflammation. These data provide a foundation for future studies exploring how KB may be used to either reverse or prevent progression of established emphysema and small airways disease associated with chronic cigarette smoke exposure. Lastly, the data suggest the intriguing possibility that $K B$, which stimulates rather than suppresses systemic immune responses, might be a novel means by which the course of COPD pathogenesis may be altered, highlighting the complex interaction between inflammation and COPD pathogenesis.

\section{Additional files}

Additional file 1: Table S1. Soluble mediator analysis in BAL fluid following placebo and KB treatment in room air or cigarette smokeexposed groups. * $p<0.05$ comparing to the group's relative control; $\# p<0.05$ comparing treated group to untreated relative control. ns $=$ no significant difference. Data are means \pm SD of 9-10 mice per group. (XLSX $39 \mathrm{~kb}$ )

Additional file 2: Table S2. Soluble mediator analysis in serum following placebo and KB treatment in room air or cigarette smoke-exposed groups. * $p<0.05$ comparing to the group's relative control; $\# p<0.05$ comparing treated group to untreated relative control. $n s=$ no significant difference. Data are means \pm SD of 9-10 mice per group. (XLSX 36 kb)

\section{Abbreviations}

ANOVA: Analysis of variance; BAL: Bronchoalveolar lavage; COPD: Chronic obstructive pulmonary disease; EDTA: Ethylenediaminetetraacetic acid; G-CSF: Granulocyte-colony stimulating factor; GM-CSF: Granulocyte macrophage colony-stimulating factor; IFNy: Interferon-gamma; LIF: Leukemia inhibitor factor; M-CSF: Macrophage colony-stimulating factor; TNFa: Tumor necrosis factor-alpha; VEGF: Vascular endothelial growth factor; IBD: Inflammatory bowel disease; TLR: Toll-like receptor
Acknowledgements

Not Applicable.

Funding

The work was funded by Mitacs and Qu Biologics.

\section{Availability of data and material}

The datasets used and/or analysed during the current study available from the corresponding author on reasonable request.

\section{Authors' contributions}

Mark B. helped design the experiments, completed the flow cytometry and the multiplex analysis, drafted and edited the manuscript. A.B. completed the animal experiments and drafted the manuscript. R.D.H., M.R.Z., and P.M.H. contributed intellectually to the experiment design and manuscript drafting. Momir B. helped design the experiments, analyse the data and edited the manuscript. H.G. helped design the experiments and edited the manuscript. S.K. helped design the experiments, analyse the data, and edited the manuscript. J.A.H. designed the experiments, completed the experiments, drafted and edited the manuscript, and oversaw the study completion. All authors read and approved the final manuscript.

\section{Competing interests}

Mark B. is an employee of Qu Biologics. A.B. was funded by a Mitacs Industry partnered fellowship with Qu Biologics. R.D.H., M.R.Z., and P.M.H. have no competing interests. Momir B. is an employee of Qu Biologics. H.G. is an employee and co-founder of Qu Biologics. S.K. is an employee of Qu Biologics. J.A.H. received consulting fees from Qu Biologics.

\section{Consent for publication}

Not Applicable.

Ethics approval and consent to participate

All studies were approved by the UBC Animal Care Committee.

\section{Publisher's Note}

Springer Nature remains neutral with regard to jurisdictional claims in published maps and institutional affiliations.

\section{Author details}

'Qu Biologics Inc., Vancouver, BC, CanadaV5T 4T5. ${ }^{2}$ Department of Medicine, Division of Respiratory Medicine, University of British Columbia, Vancouver, BC, CanadaV6H 3Z6. ${ }^{3} \mathrm{i} C O R D$ Research Centre, University of British Columbia, Vancouver, BC, CanadaV5Z 1M5. ${ }^{4}$ Priority Research Centre for Healthy Lungs, Hunter Medical Research Institute, The University of Newcastle, Newcastle, NSW, Australia. ${ }^{5}$ Department of Medicine, Division of Endocrinology, CeMCOR, University of British Columbia, Vancouver, BC, CanadaV5Z 1 M9.

${ }^{6}$ Firestone Institute for Respiratory Health, Division of Respirology, Department of Medicine, McMaster University, Hamilton, ON, CanadaL8N $4 \mathrm{~A} 6$.

Received: 2 January 2017 Accepted: 8 May 2017 Published online: 15 May 2017

\section{References}

1. Adeloye D, Chua S, Lee C, Basquill C, Papana A, Theodoratou E, Nair H, Gasevic D, Sridhar D, Campbell H, et al. Global and regional estimates of COPD prevalence: systematic review and meta-analysis. J Glob Health. 2015;5:020415.

2. Mathers $C D$, Loncar D. Projections of global mortality and burden of disease from 2002 to 2030. PLoS Med. 2006;3:e442.

3. Eisner MD, Balmes J, Katz PP, Trupin L, Yelin EH, Blanc PD. Lifetime environmental tobacco smoke exposure and the risk of chronic obstructive pulmonary disease. Environ Health. 2005;4:7.

4. Thun GA, Imboden M, Ferrarotti I, Kumar A, Obeidat M, Zorzetto M, Haun M, Curjuric I, Couto Alves A, Jackson VE, et al. Causal and synthetic associations of variants in the SERPINA gene cluster with alpha1-antitrypsin serum levels. PLoS Genet. 2013;9:e1003585.

5. Stoller JK, Aboussouan LS. Alpha1-antitrypsin deficiency. Lancet 2005;365:2225-36 
6. Abbey DE, Burchette RJ, Knutsen SF, McDonnell WF, Lebowitz MD, Enright PL Long-term particulate and other air pollutants and lung function in nonsmokers. Am J Respir Crit Care Med. 1998;158:289-98.

7. To T, Zhu J, Larsen K, Simatovic J, Feldman L, Ryckman K, Gershon A, Lougheed MD, Licskai C, Chen $\mathrm{H}$, et al. Progression from asthma to chronic obstructive pulmonary disease. Is Air pollution a risk factor? Am J Respir Crit Care Med. 2016;194:429-38.

8. Kessler R, Partridge MR, Miravitlles M, Cazzola M, Vogelmeier C, Leynaud D, Ostinelli J. Symptom variability in patients with severe COPD: a panEuropean cross-sectional study. Eur Respir J. 2011;37:264-72.

9. MJ E de I M, Pena C, Soto Hurtado EJ, Jareno J, Miravitlles M. Variability of respiratory symptoms in severe COPD. Arch Bronconeumol. 2012;48:3-7.

10. Burge PS, Calverley PM, Jones PW, Spencer S, Anderson JA, Maslen TK. Randomised, double blind, placebo controlled study of fluticasone propionate in patients with moderate to severe chronic obstructive pulmonary disease: the ISOLDE trial. BMJ. 2000;320:1297-303.

11. Vestbo J, Sorensen T, Lange P, Brix A, Torre P, Viskum K. Long-term effect of inhaled budesonide in mild and moderate chronic obstructive pulmonary disease: a randomised controlled trial. Lancet. 1999;353:1819-23.

12. Wouters EF, Reynaert NL, Dentener MA, Vernooy JH. Systemic and local inflammation in asthma and chronic obstructive pulmonary disease: is there a connection? Proc Am Thorac Soc. 2009;6:638-47.

13. McDonough JE, Yuan R, Suzuki M, Seyednejad N, Elliott WM, Sanchez PG, Wright AC, Gefter WB, Litzky L, Coxson HO, et al. Small-airway obstruction and emphysema in chronic obstructive pulmonary disease. N Engl J Med. 2011;365:1567-75.

14. Grumelli S, Corry DB, Song LZ, Song L, Green L, Huh J, Hacken J, Espada R, Bag R, Lewis DE, Kheradmand F. An immune basis for lung parenchymal destruction in chronic obstructive pulmonary disease and emphysema. PLoS Med. 2004;1:e8.

15. Brozyna S, Ahern J, Hodge G, Nairn J, Holmes M, Reynolds PN, Hodge S. Chemotactic mediators of Th1 T-cell trafficking in smokers and COPD patients. COPD. 2009;6:4-16.

16. Ma B, Kang MJ, Lee CG, Chapoval S, Liu W, Chen Q, Coyle AJ, Lora JM, Picarella D, Homer RJ, Elias JA. Role of CCR5 in IFN-gamma-induced and cigarette smoke-induced emphysema. J Clin Invest. 2005;115:3460-72.

17. MacNee W, Wiggs B, Belzberg AS, Hogg JC. The effect of cigarette smoking on neutrophil kinetics in human lungs. N Engl J Med. 1989;321:924-8.

18. Saetta M, Di Stefano A, Maestrelli P, Ferraresso A, Drigo R, Potena A, Ciaccia A, Fabbri LM. Activated T-lymphocytes and macrophages in bronchial mucosa of subjects with chronic bronchitis. Am Rev Respir Dis. 1993;147:301-6.

19. Byrne AJ, Mathie SA, Gregory LG, Lloyd CM. Pulmonary macrophages: key players in the innate defence of the airways. Thorax. 2015;70:1189-96.

20. Aryan Z, Holgate ST, Radzioch D, Rezaei N. A new era of targeting the ancient gatekeepers of the immune system: toll-like agonists in the treatment of allergic rhinitis and asthma. Int Arch Allergy Immunol. 2014;164:46-63.

21. Arrieta MC, Stiemsma LT, Dimitriu PA, Thorson L, Russell S, Yurist-Doutsch S, Kuzeljevic B, Gold MJ, Britton HM, Lefebvre DL, et al. Early infancy microbial and metabolic alterations affect risk of childhood asthma. Sci Transl Med. 2015;7:307ra152.

22. Bazett M, Biala A, Huff RD, Bosiljcic M, Gunn H, Kalyan S, Hirota JA. A novel microbe-based treatment that attenuates the inflammatory profile in a mouse model of allergic airway disease. Sci Rep. 2016;6:35338.

23. Thorburn AN, Hansbro PM. Harnessing regulatory T cells to suppress asthma: from potential to therapy. Am J Respir Cell Mol Biol. 2010;43:511-9.

24. Thorburn AN, Foster PS, Gibson PG, Hansbro PM. Components of Streptococcus pneumoniae suppress allergic airways disease and NKT cells by inducing regulatory T cells. J Immunol. 2012;188:4611-20.

25. Arnold IC, Dehzad N, Reuter S, Martin H, Becher B, Taube C, Muller A. Helicobacter pylori infection prevents allergic asthma in mouse models through the induction of regulatory T cells. J Clin Invest. 2011;121:3088-93.

26. Forsythe $P$, Inman MD, Bienenstock J. Oral treatment with live Lactobacillus reuteri inhibits the allergic airway response in mice. Am J Respir Crit Care Med. 2007;175:561-9.

27. Fujimura KE, Demoor $T$, Rauch M, Faruqi AA, Jang S, Johnson CC, Boushey HA, Zoratti E, Ownby D, Lukacs NW, Lynch SV. House dust exposure mediates gut microbiome Lactobacillus enrichment and airway immune defense against allergens and virus infection. Proc Natl Acad Sci U S A. 2014;111:805-10.
28. Mortaz E, Adcock IM, Ricciardolo FL, Varahram M, Jamaati H, Velayati AA, Folkerts G, Garssen J. Anti-inflammatory effects of lactobacillus rahmnosus and bifidobacterium breve on cigarette smoke activated human macrophages. PLoS One. 2015;10:e0136455.

29. Tam A, Churg A, Wright JL, Zhou S, Kirby M, Coxson HO, Lam S, Man SF, Sin DD. Sex differences in airway remodeling in a mouse model of chronic obstructive pulmonary disease. Am J Respir Crit Care Med. 2016;193:825-34.

30. Zhou S, Wright JL, Liu J, Sin DD, Churg A. Aging does not enhance experimental cigarette smoke-induced COPD in the mouse. PLoS One. 2013:8:e71410.

31. Budden KF, Gellatly SL, Wood DL, Cooper MA, Morrison M, Hugenholtz P, Hansbro PM. Emerging pathogenic links between microbiota and the gut-lung axis. Nat Rev Microbiol. 2017;15:55-63.

32. Hogg JC, Chu F, Utokaparch S, Woods R, Elliott WM, Buzatu L, Cherniack RM, Rogers RM, Sciurba FC, Coxson HO, Pare PD. The nature of small-airway obstruction in chronic obstructive pulmonary disease. N Engl J Med. 2004; 350:2645-53.

33. Churg A, Tai H, Coulthard T, Wang R, Wright JL. Cigarette smoke drives small airway remodeling by induction of growth factors in the airway wall. Am J Respir Crit Care Med. 2006;174:1327-34.

34. Jobse BN, McCurry CA, Morissette MC, Rhem RG, Stampfli MR, Labiris NR. Impact of inflammation, emphysema, and smoking cessation on V/Q in mouse models of lung obstruction. Respir Res. 2014;15:42.

35. Botelho FM, Gaschler GJ, Kianpour S, Zavitz CC, Trimble NJ, Nikota JK, Bauer CM, Stampfli MR. Innate immune processes are sufficient for driving cigarette smoke-induced inflammation in mice. Am J Respir Cell Mol Biol. 2010;42:394-403.

36. Beckett EL, Stevens RL, Jarnicki AG, Kim RY, Hanish I, Hansbro NG, Deane A, Keely S, Horvat JC, Yang M, et al. A new short-term mouse model of chronic obstructive pulmonary disease identifies a role for mast cell tryptase in pathogenesis. J Allergy Clin Immunol. 2013;131:752-62.

37. Hsu AC, Starkey MR, Hanish I, Parsons K, Haw TJ, Howland L, Barr I, Mahony JB, Foster PS, Knight DA, et al. Targeting PI3K-p110alpha suppresses influenza virus infection in chronic obstructive pulmonary disease. Am J Respir Crit Care Med. 2015;191:1012-23.

38. Jones B, Donovan C, Liu G, Gomez HM, Chimankar V, Harrison CL, Wiegman $\mathrm{CH}$, Adcock IM, Knight DA, Hirota JA, Hansbro PM. Animal models of COPD: what do they tell us? Respirology. 2017;22:21-32.

39. Muller M, Carter S, Hofer MJ, Campbell IL. Review: The chemokine receptor CXCR3 and its ligands CXCL9, CXCL10 and CXCL11 in neuroimmunity-a tale of conflict and conundrum. Neuropathol Appl Neurobiol. 2010;36:368-87.

40. Nie L, Xiang R, Zhou W, Lu B, Cheng D, Gao J. Attenuation of acute lung inflammation induced by cigarette smoke in CXCR3 knockout mice. Respir Res. 2008;9:82.

41. Keely S, Talley NJ, Hansbro PM. Pulmonary-intestinal cross-talk in mucosal inflammatory disease. Mucosal Immunol. 2012;5:7-18.

42. Rodriguez-Roisin R, Bartolome SD, Huchon G, Krowka MJ. Inflammatory bowel diseases, chronic liver diseases and the lung. Eur Respir J. 2016;47:638-50

43. Wasilewski A, Zielinska M, Storr M, Fichna J. Beneficial effects of probiotics, prebiotics, synbiotics, and psychobiotics in inflammatory bowel disease. Inflamm Bowel Dis. 2015;21:1674-82.

44. Matijasic M, Mestrovic T, Peric M, Cipcic Paljetak H, Panek M, Vranesic Bender D, Ljubas Kelecic D, Krznaric Z, Verbanac D. Modulating Composition and Metabolic Activity of the Gut Microbiota in IBD Patients. Int J Mol Sci. 2016;17:578.

45. Bressler B, Bethel KP, Kleef R, Reynolds SL, Sutcliffe S, Mullins DW, Gunn H. Site-specific immunomodulator: a novel treatment for Crohn's disease. Gastroenterol Res Pract. 2015;2015:231243.

46. Brassard P, Vutcovici M, Ernst P, Patenaude V, Sewitch M, Suissa S, Bitton A. Increased incidence of inflammatory bowel disease in Quebec residents with airway diseases. Eur Respir J. 2015;45:962-8.

47. Hirota JA, Carlsten C, Sadatsafavi M, Kaplan G, Hirota SA. Airway diseases and inflammatory bowel diseases: is it something in the air (pollution)? Eur Respir J. 2015:46:287-8.

48. Thorburn AN, O'Sullivan BJ, Thomas R, Kumar RK, Foster PS, Gibson PG, Hansbro PM. Pneumococcal conjugate vaccine-induced regulatory T cells suppress the development of allergic airways disease. Thorax. 2010;65:1053-60.

49. Preston JA, Essilfie AT, Horvat JC, Wade MA, Beagley KW, Gibson PG, Foster PS, Hansbro PM. Inhibition of allergic airways disease by 
immunomodulatory therapy with whole killed Streptococcus pneumoniae. Vaccine. 2007;25:8154-62.

50. Aryan Z, Rezaei N. Toll-like receptors as targets for allergen immunotherapy. Curr Opin Allergy Clin Immunol. 2015;15:568-74.

51. Miettinen M, Pietila TE, Kekkonen RA, Kankainen M, Latvala S, Pirhonen J, Osterlund P, Korpela R, Julkunen I. Nonpathogenic Lactobacillus rhamnosus activates the inflammasome and antiviral responses in human macrophages. Gut Microbes. 2012;3:510-22.

52. Dinarello CA. Immunological and inflammatory functions of the interleukin1 family. Annu Rev Immunol. 2009;27:519-50.

53. Shi C, Pamer EG. Monocyte recruitment during infection and inflammation. Nat Rev Immunol. 2011;11:762-74.

54. Rivera A, Siracusa MC, Yap GS, Gause WC. Innate cell communication kickstarts pathogen-specific immunity. Nat Immunol. 2016;17:356-63.

55. Jiang Z, Zhu L. Update on the role of alternatively activated macrophages in asthma. J Asthma Allergy. 2016;9:101-7.

56. Labonte AC, Tosello-Trampont AC, Hahn YS. The role of macrophage polarization in infectious and inflammatory diseases. Mol Cells. 2014;37:275-85.

57. Avdic S, Cao JZ, McSharry BP, Clancy LE, Brown R, Steain M, Gottlieb DJ, Abendroth A, Slobedman B. Human cytomegalovirus interleukin-10 polarizes monocytes toward a deactivated $\mathrm{M} 2 \mathrm{C}$ phenotype to repress host immune responses. J Virol. 2013:87:10273-82.

58. Zizzo G, Cohen PL. IL-17 stimulates differentiation of human antiinflammatory macrophages and phagocytosis of apoptotic neutrophils in response to IL-10 and glucocorticoids. J Immunol. 2013;190:5237-46.

\section{Submit your next manuscript to BioMed Central and we will help you at every step:}

- We accept pre-submission inquiries

- Our selector tool helps you to find the most relevant journal

- We provide round the clock customer support

- Convenient online submission

- Thorough peer review

- Inclusion in PubMed and all major indexing services

- Maximum visibility for your research

Submit your manuscript at www.biomedcentral.com/submit

) Biomed Central 